Xue-qiu He, Song Li

\title{
On Social-technical Control of Safety Development in Economic Transition Background
}

\begin{abstract}
Industrial safety and economic growth, two vital and inextricable forces affecting national culture and development, are worthy of much more interest and attention than this article can hope to generate. Following economic growth, industrial safety remains as a high priority in this nation's quest for sustainable development. At present, while China is on its way to transforming its economic structure and growth models, talk of industrial safety appears with special regularity, for it also is undergoing profound changes as an important facet of modern China.
\end{abstract}

Keywords: safety development, economic growth, economic transition, social-technical control

\section{Introduction}

In the 21st century, China's manufacturing has become the leader of industries undertaking international expansion. However, along with rapid development of industrialization and urbanization, industrial disasters have mushroomed. Accidental disasters have not only resulted in significant casualties, endangering people's lives, but have also been horrific in terms of economic losses. Since 2000, the frequency of accident disasters has been effectively controlled as a result of the government's supervision of work safety. Even so, the death toll is still high. Each year, workplace accidents account for over 1 million fatalities, 70 million seriously disabled, and some 250 million people working in dangerous workplaces exposed to dust, poisons, and noise (Fan, 2003). Catastrophic accidents highlight vulnerable work groups, social injustices and corruption. Needless to say public opinion regarding safety has been

Manuscript received February 19, 2015; accepted June 7, 2015

Xue-qiu He $(\bowtie)$

School of Civil and Environment Engineering, University of Science \& Technology Beijing, Beijing 100083, China

Email: hexq@chinasafety.gov.cn

Song Li

Anhui University of Science and Technology, Huainan 232001, China raised. Safety development is beyond the scope of technology, and becomes a political problem related to peoples' livelihood, social and economic development. "Safety Development" was established in China as the guiding principle for production and development, and for building a harmonious socialist society (State Administration of Work Safety, 2007). How to pursue economic growth with safe and sustainable development has become the primary goal. Workplace activity is necessarily and closely related to economic and social development. At present, while our country is in a key historical period of transforming economic structures and changing economic growth modes, work safety is undergoing profound changes and has taken on special significance. Therefore, this article analyzes social-technical methods of safety based on effects arising from current economic growth.

\section{Impact on work safety due to economic growth}

2.1 Convergence features of occupational fatalities and economic cycle

China's national economy has developed rapidly and fluidly since the founding of new China. Figure 1 compares economic growth rates from 1952 to 2008 . The outstanding feature of economic cycles before 1978 was continuous ups and downs. The average fluctuation rate reached $21.98 \%$. In a word, China's economy was poor (Wang, 2001). Gross Domestic Product (GDP) presented negative growth in the declining stages of economic cycles. Meanwhile the annual fatality rate per 100,000 workers presented a considerable challenge to leaders throughout the nation. The first accidents peak appeared during 1958-1961, "The Great Leap Forward" political movement destroyed the normal order of social production, the fatality rate rose sharply while the GDP growth rate plummeted. At that point, the annual death toll rose to 12,850 in 1958 from 3,704 in 1957. By the end of 1961, the GDP growth rate had bottomed out. The second accidents peak appeared during 1970-1979. During that period, the Cultural Revolution 


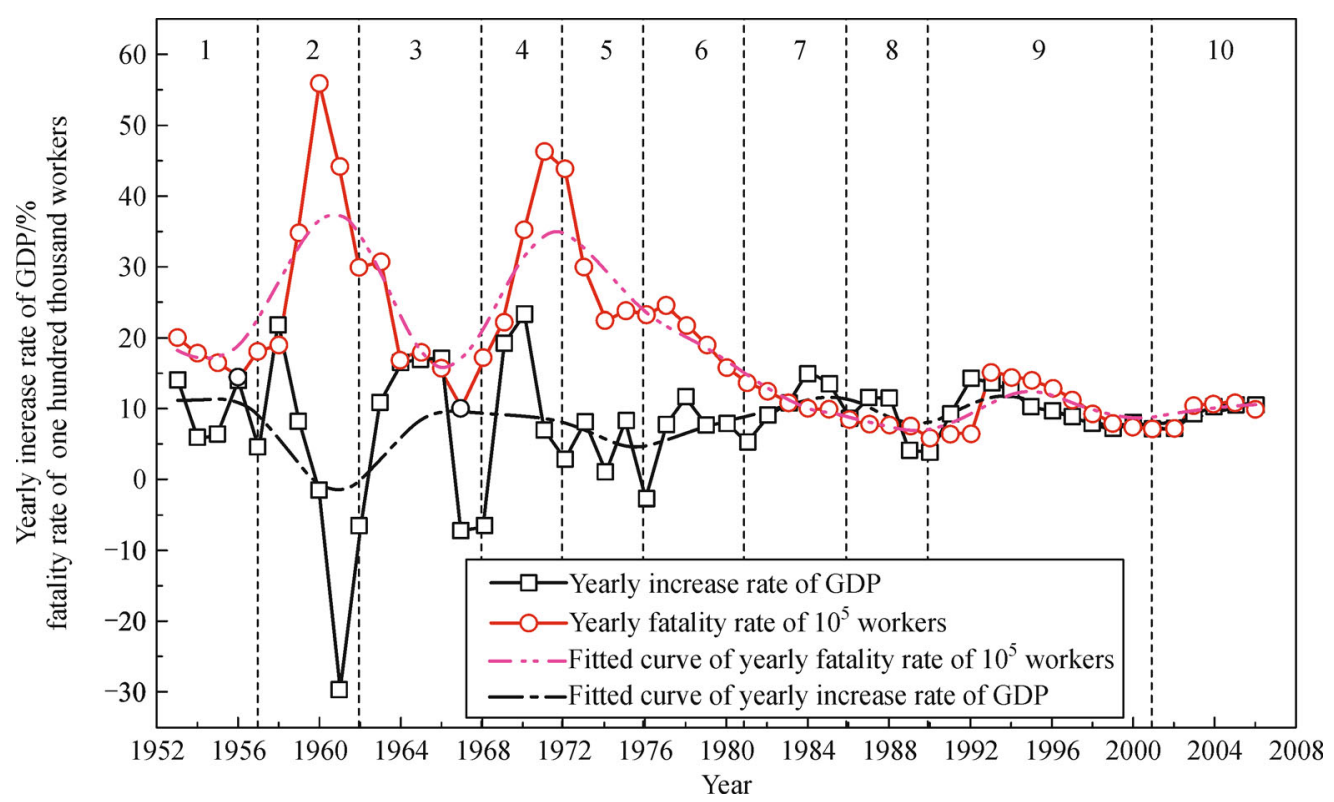

Figure 1. Trends of fatality rate per 100,000 workers and economic cycles in China, 1953-2008 (Song, He \& Li, 2011).

political movement, all safety agencies of mines and factories were cancelled. The Work safety administration closed as did all legal construction. After the reform and opening-up, the market economy strengthened the selfadjusting ability of China's economic system. China's economic growth rate appeared as a gentle fluctuation (The Chinese Academy of Social Sciences Industrial Economy Research Institute, 2006). The standard deviation, which can reflect fluctuation range, declined to $2.9 \%$ from $10.5 \%$ before the reform. The annual fatality rate per 100,000 workers slowly declined from 1993 up to now, with the exception being the period from 2001 to 2003 . Shown as in Figure 1, the track of fatality rate per 100,000 workers was consistent with economic development track.

A world economic crisis has evolved since August 2007. Developed country economies have been impacted by the crisis to a great extent. The Chinese economy has also faced heavy pressures. Figure 2 compares trends of quarterly speed of economy with that of quarterly occupational accidents case counts during 2007-2009. Quarter growth rate of GDP declined sharply from the second quarter of 2007 and bottomed out in the first quarter of 2009. Meanwhile quarterly occupational accident cases declined quickly. The GDP quarterly growth rate began to rise since the first quarter of 2009. Quarterly occupational accident cases rose accordingly. This phenomenon proved that economic cycle could correspond to work safety to some extent and economic speed was an important indicator to work safety in China.

2.2 Economic growth structure effect on work safety risk

Industrial structure refers to the ratio of production factors

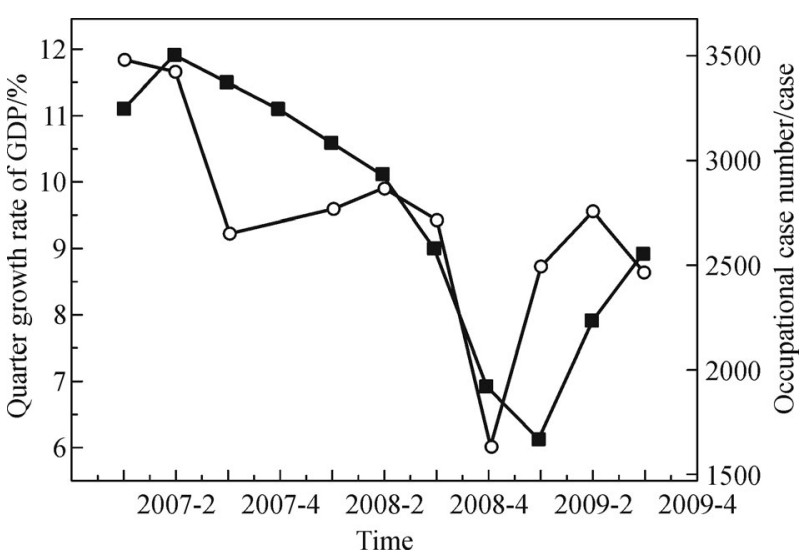

Figure 2. Trends of quarterly GDP growth rate and the number of occupational accident cases (Song, He \& Li, 2011).

distributed in various industrial sectors and mutual relationships among them, namely allocation and interaction among capital, human resources, natural resources and material resources in a country or region (Yang \& Zhang, 2008). Due to differences in technical progress levels, resource endowment, demand, or supply, elasticities, a country or regional industrial structures will change with economic growth. In modern economic growth, industrial structures closely relate to economic development, and the status of the industrial structure and economic structure reflects a country's economic development direction and development stages, and restricts the economic growth rate. Industrial structure is the key factor influencing economic growth, and the merits of the industrial structure demonstrate the quality and the stage of economic development. 
American economist Kuznets (1989) thinks that along with economic development, agriculture declines proportionally while both industrial sectors and service sectors increase. Industrial proportion in the national economy will present an inverted "U" type changing process.

Dangerous workplaces and work processes are the sources of accidents (Rasmussen, 1997). Due to differences in energy, dangerous and harmful substances, and personnel density at various workplaces, different industries show different worker safety risks. Thus the change to industrial structure not only reflects inputs and equilibrium relationships among economic growth factors, but also reflects work safety risk distribution. In Figure 3 and Figure 4, a comparison is presented of the work accident cases and death toll among three sectors, respectively. Industries with significantly higher risk mean that if a country or region's economic structure features high industrial proportion, it faces higher worker safety pressure.

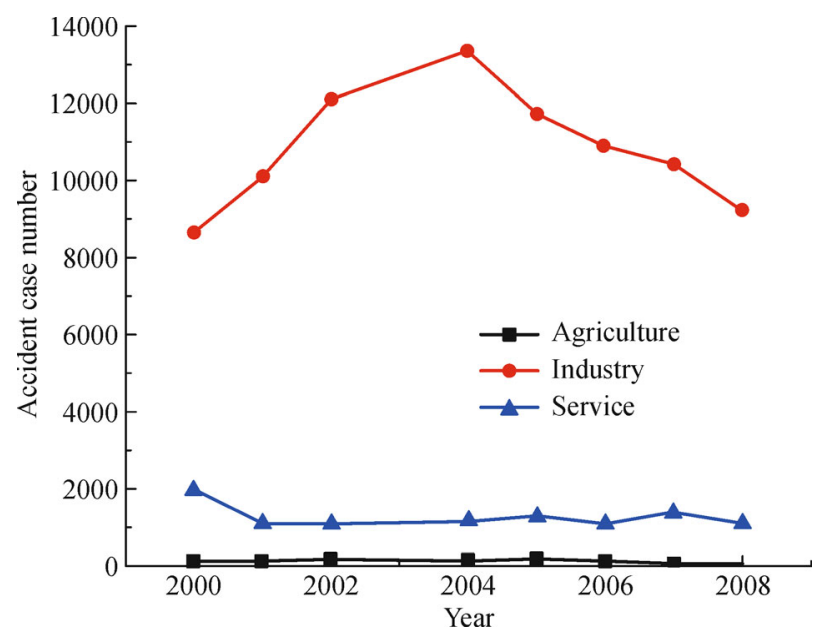

Figure 3. Accident cases in 3 economic sectors.

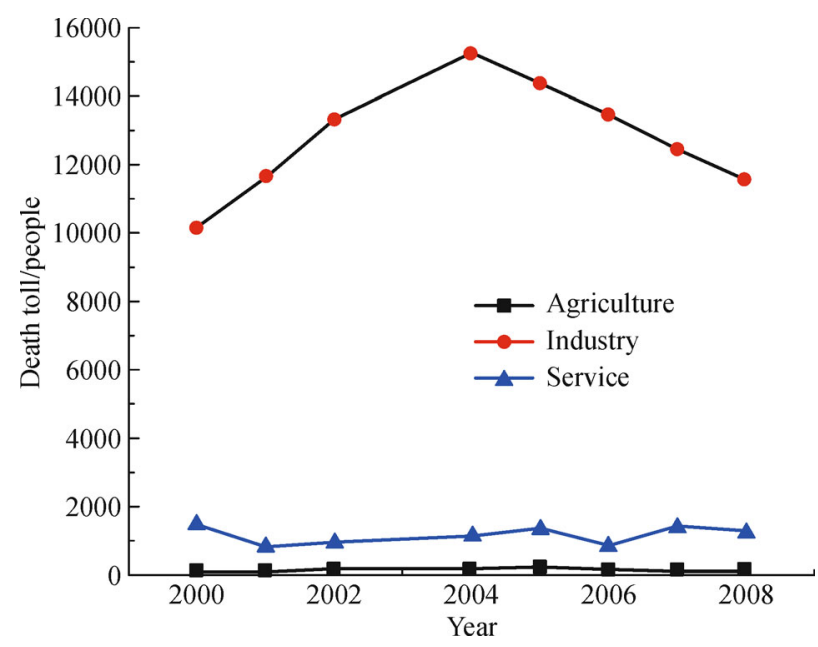

Figure 4. Death toll distribution in 3 sectors.
2.3 Asymmetry of production technology and safety technology

Technological advances can be summarized as the development process of social productivity promoted by improving the efficiency of capital and labor using advanced instruments and techniques. A majority of technological advances are born of social production, and technological advances focus on production technology that emphasizes reducing production costs and increasing resource utilization rates. Production technology advances are able to bring enormous wealth and promote economic growth. On the other hand, demand for worker safety can promote safety science and technology, the aim of which is to reduce accidents by way of improving the technical reliability of the production system. However, the market is a tool of optimizing resources allocation and pursuing efficiency. Market forces would be apt to accelerate and optimize resources with market value, but be powerless toward external resources. Work accidents usually bring loss to labor, environment, and eventually to the general public. But losses occurring outside the market cannot be bounded by market power. As to safety technology, which usually has a long market cycle and lower input-output ratio, will not develop without support of government, social demand and public pressure. Thus it is inevitably that there is an asymmetry between production technology and safety technology. In fact, the process of compensation for the accident loss and risk control is promoted by means of market prices.

Small and medium-sized enterprises have developed rapidly since the Reform and Opening policy. Small and medium-sized enterprises operate mostly with backward technology and have high work safety risks. Nowadays, a majority of gem and mineral mines are private small businesses with backward production techniques and low labor productivity. Many underground mines are explored by conventional means. As a result, underground mining is probably the most backward industry in China (Rasmussen, 1997). Small open-pit mines are usually operated with lower technology equipment, with many working procedures requiring hand-held tools. Small-scale enterprises are disadvantaged compared to high-tech companies on account of diseconomies of scale. Some work accidents occurred just because the enterprises were lacking basic safety and survival equipment.

2.4 Human error is the most important factor influencing work safety

In the process of social production, many factors such as hardware instability, human behavior and inharmonious environment all disrupt the system behavior and make it fluctuate. Once the fluctuations surpass the safety capability of the system, the production process would be 
interrupted, and work accidents occur. Therefore, operating systems should be designed to respond efficiently to human error and to improve system safety adaptability. Many accident investigations have proved that human error is a key factor influencing work safety. For example, the combination of wrong management decisions, unsafe worker behavior and inadequate safety defense leads to accidents (Reason, 1990). Under the circumstance of rapid technique progress and dynamic environment, worker knowledge, skills and learning ability are important factors strengthening safety system adaptability. The quality of human capital not only influences production efficiency and economic growth, but also affects work safety. It is necessary to reduce work risk by improving worker safety knowledge and skills.

A cheap and abundant labor force is beneficial to keep competitive advantage on labor costs and makes China labor-intensive economy grow rapidly with lower running costs, industrial upgrading demands developing high-tech industries and emerging industries along with rapid industrialization. Technological changes are rapid in many operational fields such as transportation and manufacturing. However, China industrial workers have lower cultural quality and professional qualities. Advanced techniques and machines are short of skilled workers. On the one hand, these technical fault phenomena affect enterprise abilities to absorb new industrial technology and bring low labor productivity; on the other hand, these technical fault phenomena increase work safety risk. This is because the skills and learning ability of human resources including workers, engineers and management are key factors reducing the risk of technology transfer. First line workers must accurately operate machinery and equipment, and then advanced technology can be used to improve industrial efficiency and reduce unsafe behavior.
With the acceleration of industrialization and urbanization, a large surplus agricultural labor force has transferred to non-agricultural sectors continuously making Chinese industrial work structure change. Migrant workers have become the main part of the industrial work force. Many labor-intensive small and medium-sized enterprises give preference to migrant workers for their lower labor cost, and a majority of migrant workers have been put on positions with high work risk. They usually lack professional quality and are under high financial pressure, which not only increases human error such as violating rules, but also increase difficulty of safety supervision. Accidents investigation proved that migrant workers are main vulnerable groups to work disasters. It is urgent for work safety by improving industrial workers' professional quality and safety skills.

\subsection{Economic transition affects work safety}

Before the Reform and Opening Policy, China's economy was basically a single public ownership economy. A series of systemic economic reforms have been put into practice since 1978 along with constant perfection of a market mechanism. Great changes have taken place in ownership of China enterprises, new kinds of enterprises ownership coexist including township enterprises, private enterprises and foreign enterprises. With the rapid development of the non-state-owned enterprises and labor employment system reform, work safety has taken on a new look. Figure 5 describes death toll distribution for various ownership enterprises. Leading are accident-caused deaths occurring in private and limited liability companies. Deaths occurring in the private enterprise economy showed a trend of rapid rise before 2004 and declined fast after 2004, while that of limited liability companies have steadily fallen since its

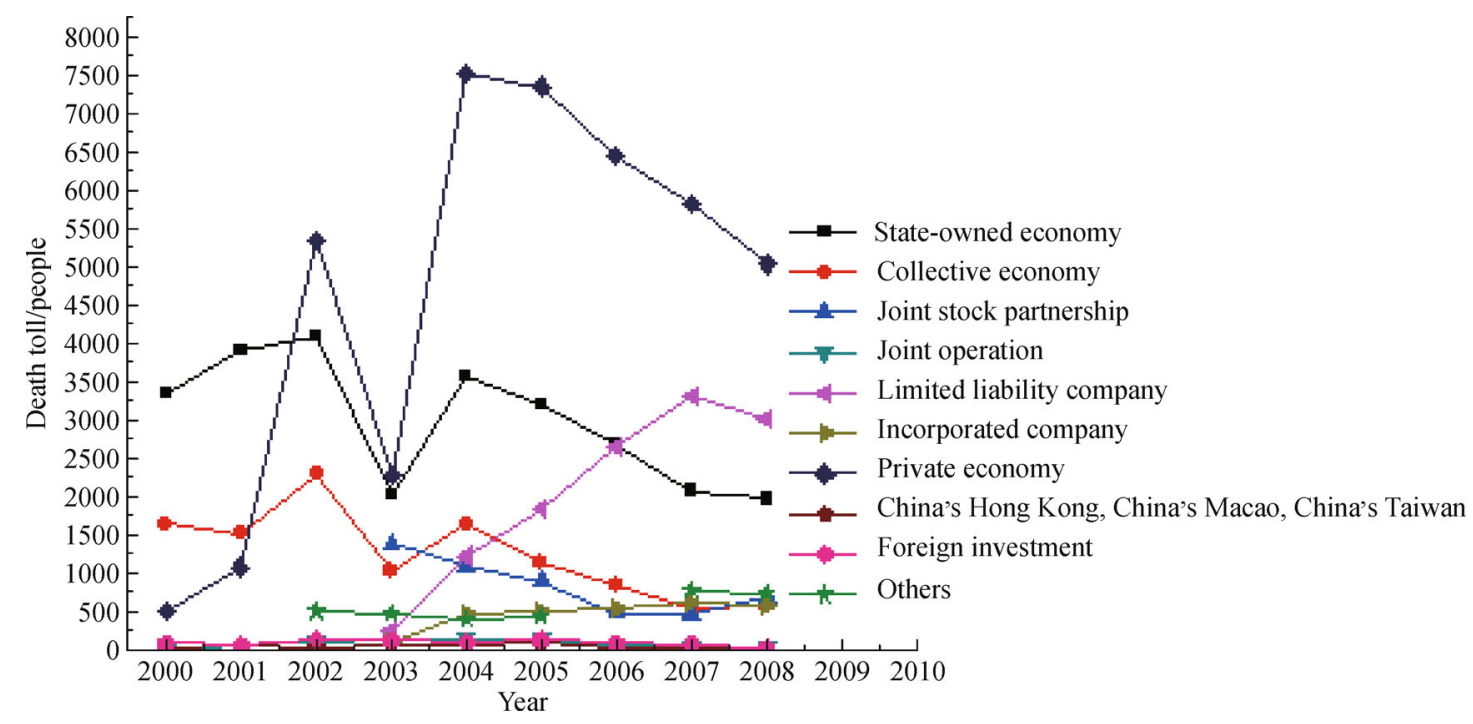

Figure 5. Death toll distribution in various ownership enterprises. 
peak in 2007. Other ownership enterprises have maintained a steady downward trend.

\section{Social-technique control of safe development in economic transformation background}

Close relationships between work safety and economic growth show that disasters are not entirely owing to natural forces or technical defects. It is with human activities that losses rise. China is now on the path of economic integration, quick industrialization and urbanization, rapid economic and political system reform; therefore disasters are more complicated than in most other countries. It is necessary to understand industrial disasters from a broad perspective, to expand the thinking space of safety development, to promote integration of work safety and economic and social development.

\subsection{Technical control of safety development}

\subsubsection{Production technology control}

Technology is both a key to promote economic growth and an important tool to control work safety risk. Accidents are consequences of objective variation. Suitable technical support systems for social production could not be set up without revealing the essential reasons and technical reasons for accidents.

Developed countries such as the United States, Japan and Germany all attach importance to relying on scientific and technological progress to ensure worker safety. National safety technology research institutions are set up to carry out safety theory research, explore major scientific research projects, popularize advanced technology, and control major disasters. Some countries such as Japan and the United States usually put forward technology compilation and comprehensive analysis on major typical accidents, and revise the relevant standards, rules and regulations accordingly, which turn accident lessons into treasure.

3.1.2 Putting work safety risk assessment into the industrial technology policies

Advanced science and technical equipments can improve intrinsic safety ability of production systems. Therefore, it is necessary to blend work safety risk in technology introduction and innovation strategy at the macro and micro levels. Chinese work accidents are concentrated in small and medium-sized enterprises, the most important causes are limited financial power and backward production technology. It is necessary to use technical policies encouraging enterprises to adopt production modes and processes with lower inherent safety risk.

3.1.3 Promoting the development of safety science and technology

As an important part of science and technology, safety science and technology are sources of potential productivity, which can be transformed into direct productivity by a series of intermediate processes. Owing to asymmetry between production technology and safety technology, safety science and technology usually lags behind production technology. At present, there are a large number of workers exposed to occupational hazards due to a lack of necessary protective equipment. There are serious potential safety hazards in the high-risk industries that are short of safety investment. Therefore, the Government should promote the development of safety science and technology and popularize safety technology.

\subsection{Social control of safety development}

\subsubsection{Goal coordination of economic policy and work safety policy}

(1) Incorporating safety risk control into the industrial structure adjustment strategy

Within the background of economic globalization, China's industrial structure adjustment and evolution would not be isolated from global industry development, thus must be affected by rules of international industrial transfer. China industries are entirely on the lower side of the international industrial chain, which make China a key area to undertake manufacturing technology transfer over a rather long period. Mining and manufacturing industries have a higher work risk, a low average production technical level and lower skilled workers who increase human error risk. These factors make mining and manufacturing industries leading entities in the national industry-related death toll. China current economy has stepped up to a new stage, where the mode of economic growth is unsustainable. It is a fundamental responsibility to keep a sustainable development by promoting economic restructuring and changing its economic development pattern (He \& Song, 2015). Hence it is necessary to integrate work safety risk control into the industrial structure adjustment strategy.

(2) Integrating work safety risk assessment into economic system reform strategy

China's economy system changes features with the growth of the non-state economy. On the one hand, the rapid development of the non-state economy promotes social progress and wealth growth. On the other hand, the non-state economy shows serious work accidents risks owing to coupling of backward production technology, labor-intensive production mode and over-crowding groups of migrant workers. Changes in the economic 
system are changing the safety environment in the workplace to a certain extent, first influencing the complex social-technical system, and then affecting accident disasters. In 2002, the Sixteenth National Congress of the Communist Party of China continued to adjust the layout and structure of the state-owned economy, promote stateowned economy reform by methods of joint-stock system, shareholding co-operative system and attracting foreign investment. Accident-caused deaths occurred in private and limited liability companies showing a trend of rapid rise since the year of 2003, while that of other ownership enterprises declined fast. The phenomenon suggests that restructuring, merger and reorganization of enterprises can change organizational structure, affect employees' work psychology and behavior, which may increase human and organizational risk at the early stage. Therefore, it is especially necessary to strengthen work safety supervision in the process of enterprise reform and defuse negative impact on work safety caused by a series of social and economic factors.

\subsubsection{Behavior control of safety production main body}

(1) Incentive compatibility of the system design

In the process of social production, enterprises are not only important factors promoting economic growth but also source-causes of accidents. Safety administration aims to guide enterprises to carry out necessary safety investments. At present, China's work safety administration system is "government regulation, enterprise responsible". Enterprises are responsible for work safety. As profitpursuing organizations, the enterprise goal is to maximize profits. When the cost of abiding by safety regulation is greater than that of violating safety regulation, enterprises lack safety investment motivation, produce beyond their capability, and ignore safety training. Therefore, in order to achieve the ultimate goal of reducing accidents, cost benefit analysis should be strengthened in the supervision system design, focusing on cost benefit analysis, internalize accident cost by means of market.

(2) Enhancing internal counterbalance power by strengthening workers' unions

Enterprises would, during the pursuit of maximizing economic benefit, lack enough supervision, where management usually regards safety investment as a cost to control, pays little attention to improving the workplace environment and strengthening worker safety training. The case will be more serious when enterprises meet stressful financial pressures in the competitive market environment. At present, China's worker unions have little power to protecting employees in the workplace. Grass-roots workers (especially migrant workers) lack collective bargaining power with their enterprises. Thus work safety demand of employees is in a weak position and is not given sufficient attention. It is difficult to effectively implement the principle of "the masses supervision". Therefore, on the one hand, it is necessary to protect employee rights to know the safety risks at workplaces, strengthen safety training, and encourage employees to actively participate in safety management. On the other hand, it is imperative to develop worker union power, establish a collective bargaining system, improve worker bargaining power with their employers and make workers be a balance of power to influence safety behavior of enterprises.

(3) Developing external counterweight by improving the public safety cognition and participation awareness

Worker safety accidents may diffuse to generate public safety risk and lead to terrible injuries and financial losses. Owing to the social structure of "big government" and "small society", the power of the government penetrates into every corner of the society. This weakens the power of civil society.

At present China has adopted a government-oriented safety administration. Social and economic transformation puts forward new requirements on safety administration, command-forced control by the government has not adapted to the needs of the changing situation. Safety administration systems should be transformed from divisional management to public management with emphasis on extensive participation and supervisory mechanism.

\section{Conclusions}

(1) There is a close correlation between economic growth and industrial safety. Economic structures and economic cycles correspond to work safety and show signs of significant negative structure effects. Industry is the key structure affecting industrial safety. Asymmetry in technical progress means that the prevention and control of industrial accidents is inseparable from technological progress. Economic systems changes may break the balances of social factors and technological factors so as to increase work safety risk. In the process of economic system reform, enterprises should strengthen monitoring work safety risk and effectively resolve negative impacts on the workplace safety.

(2) Work safety risk control is not simply a technical problem, but a social and economic problem. It is inevitable to seek a set of comprehensive treatment composed by technical, social and economic factors. The coordination of work safety and economic growth must be dealt with using massive public policies at macro level.

(3) Presently China has entered into a new normal economic development stage; economic growth rate is from high speed to high-middle speed. The pattern of economic development is from extensive growth to intensive growth, and economic development power is from factor-driving to innovation-driven. On the one hand, these major changes in economy field have increased 
potential workplace dangers. On the other hand, it provides historical opportunity for the development of industrial safety.

\section{References}

Fan, W. (2003). Status, Gap and Countermeasures of China Work Safety. Beijing: Coal Industry Publishing House

He, X., \& Song, L. (2015). Introduction to Safety Development and Economic Growth. Beijing: Science Press

Kuznets, S. (1989). Modern Economic Growth. Beijing: Beijing Institute of Economics Publishing House

Rasmussen, J. (1997). Risk management in a dynamic society: a modeling problem. Safety Science, 27(2), 183-213
Reason, J. (1990). The contribution of latent human failures to the breakdown of complex systems. Philosophical Transactions of the Royal Society of London. Series B, Biological Sciences, 327(1241), 475-484

Song, L., He, X \& Li, C. (2011). Longitudinal relationship between economic development and occupational accidents in china. Accident Analysis \& Prevention, 43(1), 82-86

State Administration of Work Safety. (2007). Report to the Development of China's Safety Production. Beijing: Central Literature Press

The Chinese Academy of Social Sciences Industrial Economy Research Institute. (2006). China's Industrial Development Report 2005. Beijing: Economic Management Publishing House

Wang, H. (2001). New China Industrial Economic History (1979-2000). Beijing: Economic Management Publishing House

Yang, D., \& Zhang, H. (2008). Introduction to Industrial Structure. Beijing: Intellectual Property Publishing House 